\title{
REGULACIONES CULTURALES Y VIOLENCIA. RECIENTES DEBATES EN EL MOVIMIENTO DE MUJERES Y QUEER EN AMÉRICA LATINA
}

\author{
FABRICIO FORASTELLI \\ Universidad de Buenos Aires (Argentina) ${ }^{1}$
}

\begin{abstract}
¿Cuándo y por qué es necesario entender los procesos de producción de diferencia cultural y diversidad social en términos de conflicto, y cómo pensar su transformación no violenta? ¿Cómo ha sido articulada esta preocupación en la reflexión de algunos grupos de mujeres y queer en América Latina recientemente? En el presente artículo reflexionaré sobre los modos en que la crítica cultural y feminista y queer latinoamericana ha pensado la encrucijada entre la represión y la discriminación como modos de regulación de la violencia en las democracias actuales. Para ello sostendré una fórmula muy general: el pasaje del conflicto a su transformación tiene que dar cuenta de un límite inmanente del poder democrático, de una negatividad e imposibilidad que el respeto cultural vuelve posible. Pero esta negatividad ya no puede pensarse desde el lugar universal o una comunidad homogénea de sujetos, sino desde los antagonismos que participan históricamente en la formulación de lo que es posible e imposible en un proyecto comunicativo para la paz.

Primero consideraré un argumento relevante para los estudios para la paz: ¿bajo qué condiciones se está realizando la reflexión sobre los estudios de géneros? En segundo lugar, revisaré dos temas de los movimientos de géneros y minorías sexuales en América Latina: su profesionalización y «tercerización» y su carácter anti-discriminatorio y anti-represivo. Para ello revisaré dos posiciones claves en los debates latinoamericanos: la despolitización del movimiento de mujeres en la transición democrática chilena, y la intersección entre mujeres y lo queer en Argentina. Finalmente, intentaré integrar mi argumento a la línea sobre estudios para la transformación pacífica de conflictos.
\end{abstract}

1. Este artículo se escribió durante mi estadía como investigador invitado en la Cátedra UNESCO de Filosofía para la Paz de la Universitat Jaume I de Castellón. 


\section{EL MODELO FEMINISTA EN LOS ESTUDIOS PARA LA PAZ}

Desde hace años se realizan esfuerzos importantes ${ }^{2}$ por la inclusión de la perspectiva de los géneros sexuales en los Estudios para la Paz. Esta tarea requiere de una agencia humana comprometida con el respecto cultural y la educación, y tiene como objetivo la transformación no violenta de conflictos. En esta transformación resulta clave la afirmación de Vicent Martínez Guzmán de que el conflicto es constitutivo de nuestra experiencia de la Paz, pero no ineludible, y que su transformación está inscrita, al mismo tiempo como posibilidad e imposibilidad, en las narraciones de toda cultura ${ }^{3}$. Mientras no introduce sistemáticamente teoría feminista en su propuesta concreta, sí abre alternativas para considerar productivamente las reservas que algunas especialistas de estudios de géneros sexuales realizan a los Estudios de la Paz de obliterar las contribuciones de los estudios feministas sobre conflictos y pacificación.

Catia Confortini ${ }^{4}$ ha revisado la noción de poder en los estudios para la paz desde la teoría de los géneros sexuales, ya que considera que el lenguaje de la violencia está intrínsecamente relacionado con las dicotomías que articulan la diferencia de géneros. Para Confortini la idea de poder que propone Johan Galtung sobre las tres formas de violencia (directa, estructural y cultural) tiene como efecto indeseado lo que ella denomina una "naturalización» de la violencia en la sociedad, que entre otras consecuencias representa a la mujer como víctima e ignora sus reclamos específicos ${ }^{5}$. Por otro lado, no se trata de concebir la violencia de género como una sub-región del tema de la violencia en general, sino como una práctica social que provee de un acceso privilegiado a su funcionamiento.

Al considerar la relación entre violencia personal (que tiene un actor) y estructural (en la que el actor es irrelevante, ya que estaríamos a nivel de una sociedad estructurada por la violencia), Confortini señala que «Las feministas del tercer mundo están similarmente [a la propuesta de Galtung] preocupadas con las estructuras de desigualdad y la distribución desigual de recursos materiales e inmateriales» ${ }^{6}$. Y más adelante, comentando el tema de la tortura en Human

2. Por ejemplo, Vicent Martínez Guzmán observa que «necesitamos nuevos hombres y mujeres, nuevas masculinidades y feminidades que, superando la dominación masculina, construyan las relaciones entre hombres y mujeres desde la tensión entre la igualdad y la diferencia (...) sí es cierto que en la construcción social de las relaciones humanas, en la construcción social del género, como venimos mencionando desde el primer capítulo, la dominación masculina ha hecho que los hombres reivindiquen como 'hombría actos e instituciones violentas y se ha reservado para las mujeres la ternura y el cuidado relegado a la vida privada. En nuestra propuesta necesitamos más valores de las mujeres en la vida privada y pública, un desaprendizaje de los valores violentos y un nuevo aprendizaje de la ternura y el cariño por parte de los hombres». MARTíneZ GUZMÁN, Vicent: Podemos hacer las paces. Reflexiones éticas tras el 11-S y el 11-M, Bilbao, Desclée De Brouwer, 2005, pp. 87-88.

3. Ibíd.

4. Confortini, Catia: "Galtung, Violence and Gender: The Case for a Peace Studies/Feminism Alliance», Peace and Change, 31:3 (julio 2006), pp. 333-367.

5. Ibíd., p. 335.

6. Ibíd., pp. 336-337. 
Rights in Another Key también de Galtung, acuerda con que la violencia estructural no es una infracción de los derechos humanos individuales, sino "una de las estrategias del capitalismo" para producir control social ${ }^{7}$. De este modo, la violencia estructural es invisible y aparece como algo a descubrirse a través de la violencia directa, y sugiere que esa invisibilidad de la violencia estructural es la misma forma cultural del imperialismo tardo-capitalista.

Las contribuciones de los estudios de género consisten, por un lado, en especificar la relación entre el carácter estructural de la violencia y su sujeto social y, por otro, en explicar los modelos de poder involucrados en los procesos para su autorización cultural. El entendimiento de estos modos de violencia se obtiene a partir de analizar la violencia cultural través de sus intersecciones con el patriarcado. Y aquí Confortini critica a Galtung su confusión entre sexo y género, ya que oblitera tanto la variedad de feminismos como de formas que adquiere el patriarcado. En efecto, mientras se reconoce la opresión a través de las diferencias genérico-sexuales, Confortini indica que las ambigüedades en Galtung instalan el debate sobre géneros sexuales y pacificación en una paradoja: ¡el patriarcado es una estructura que causa violencia a todos los niveles o sólo una trama histórica particular de la relación entre hombres y mujeres?

Sabemos que el feminismo va a plantearse esta pregunta a través de integrar la segunda opción en la primera; por ejemplo, el concepto de las feministas inglesas de que "lo personal es político» va a ser solidario de la noción de que "la biología no es un destino». El patriarcado refiere a los procesos materiales y simbólicos de opresión y discriminación en la que está involucrada la misma estructura de los géneros, y por lo tanto se debe dar cuenta de un sujeto por definición colectivo y heterogéneo. La heterogeneidad de reclamos de las mujeres ha tenido como objetivo al mismo tiempo aspectos de igualdad (igualdad de salario por el mismo trabajo y de oportunidad de acceso a bienes sociales y económicos) y de diferencia (derechos reproductivos e independencia económica). Lo que articula esta diversidad no es sólo la compatibilidad de sus agendas sino que, en ambos casos, la satisfacción de esos reclamos implica diversos grados en la emancipación de la mujer en una sociedad dominada por hombres. Es cierto que, como indica Mora Lloyd ${ }^{8}$, la variedad de sus teorías y prácticas ha definido un espectro en el que las feministas liberales tienden a enfatizar la «igualdad de la naturaleza masculina y femenina», mientras las feministas «socialistas utópicas» acentúan la diferencia. Pero esta tensión entre igualdad y diferencia ha señalado históricamente el terreno de la emancipación femenina, y no solamente impedido su desarrollo y efectividad. Pues lo que caracteriza a ambas líneas es ser "un movimiento para la transformación social», aunque existan desacuerdos sobre cómo realizarla?.

7. Ibíd., p. 338.

8. LLOYD, Mora: «Feminism», en Adam Lent (ed): New Political Tought. An Introduction, Londres, Lawrence and Wishart, 1998, p. 164.

9. Ibíd., p. 167. 
La centralidad que adquiere el concepto de diferencia, entonces, es relevante en la medida en que su articulación específica en el contexto de feminismos diversos nos permite analizar la formación de nociones de poder sexualmente diferenciadas, pero también su agencia como modos de autorización normativa de la acción. Betty Reardon ${ }^{10}$, por ejemplo, ha entendido la relación entre igualdad y diferencia como una tensión interna al patriarcado respecto de la seguridad y el conflicto, y no simplemente un producto de la dispersión feminista ${ }^{11}$. Así, cuando analiza el sentido de "conexión» como característico del feminismo para la paz, indica en la dirección propuesta por Confortini que «el desarrollo y la paz son deseos humanos profundos que están frustrados por la presente distribución de poder ${ }^{12}$. Para Reardon, en la medida en que el modelo de desarrollo y de seguridad predominante como ideal universal es el masculino, éste se caracteriza no sólo por producir una distribución sexual del trabajo, sino por perpetuarla. Por eso, cuando afirma que la resolución de conflictos desde una perspectiva femenina busca "justicia y equidad más que victoria y retribución", ya asistimos a un modelo alternativo y viable de poder que cuestiona la distribución del trabajo así como sus fundaciones culturales. En este contexto, la pregunta que se realizan las feministas latinoamericanas es ¿cómo reconstruir las distinciones básicas de las libertades y mantener su potencial democrático cuando asistimos a la conversión de la crisis económica en una crisis general del ordenamiento social?

\section{IGUALDAD Y DIFERENCIA: TEORÍA CULTURAL FEMINISTA EN AMÉRICA LATINA}

Esta tensión entre igualdad y diferencia en la formulación del conflicto tiene características específicas en América Latina, ya que lleva a intensificar la relación entre poder patriarcal y diferencia cultural como resultado de tipos específicos e históricos de violencia. Recientemente Ileana Rodrígue $z^{13}$ ha propuesto que el vínculo entre los modelos de poder y diversidad en América Latina debe pensarse en un terreno definido por una tensión entre la resignificación cultural de las narrativas emancipatorias y el realineamiento de las fuerzas conserva-

10. Por ejemplo, ver READON, Betty: «Women's Vision of Peace. Images of Global Security», en J. Turpin y L.A. Lorentzen (eds.): The Gendered New Order. Militarism, Development and the Environment, New York y Londres, Routledge, 1996, pp. 211-235.

11. He observado en otro lugar, que la misma dispersión de posiciones se produce como efecto de un enfrentamiento a modos de dominio y autoridad. Así tiene que analizarse en el contexto de una proliferación de reclamos y no sólo como resultado de una diferenciación cultural. ForASTELLI, Fabricio: «Políticas de la restitución. Identidades y luchas sexuales en la Argentina», en F. Forastelli y X. Triquell (comps.): Las marcas del género. Configuraciones de la diferencia en la cultura, Córdoba, Centro de Estudios Avanzados-The British Council, 1999, pp. 117-141.

12. REARDON, Betty: Women's Vision..., op. cit., p. 213. Las voces de las mujeres respecto de la seguridad y la transformación de conflictos «enfatizan conexión sobre separación; entendimiento y aceptación sobre evaluación; colaboración sobre competición; discusión sobre debate; y dan tiempo para que el conocimiento emerja de la experiencia de primera mano» (p. 212).

13. Entrevista a RODRíGUEZ, Ileana, concedida para el volumen VILLORIA, Maite; FORASTELLI, Fabricio y CEDEÑ̃, Jeffrey (eds.): Estudios Culturales Latinoamericanos, Quito, Abia-yala, en prensa. 
dores a través del terrorismo de Estado. Las nociones de crimen y terrorismo han dado lugar «a lo que se entiende por ingobernabilidad y justifican políticas estatales absolutas como son la guerra, la clausura del debate so pretexto de la seguridad, los alineamientos mundiales coordinados y la puesta en escena de un mega-estado y un mega-ejército». Rodríguez denuncia la institucionalización de una guerra a los "pobres», los "descalificados» y los "desechables», quienes a su vez se organizan en la "política de la desesperación" de los movimientos populares (piqueteros, sin tierra, campesinos o indígenas pero también maquiladoras, prostitutas y travestis). Estos nuevos sujetos populares se piensan a partir de un doble movimiento crítico. Por un lado, las formas de resistencia propuestas por las mujeres y los márgenes ponen en crisis el concepto de clase para explicar la opresión; por otro lado, los nuevos sujetos populares se piensan desde la desarticulación de formas laborales legales, y por lo tanto como un problema de ley y orden. Así, asistiríamos en el neoliberalismo latinoamericano a lo que se denomina «la feminización del trabajo y la pobreza», en el que el aumento de participación de las mujeres en el mercado laboral ha sido correlativo a su precarización, informalidad y marginalidad ${ }^{14}$.

En una dirección similar, Francine Masiello en The Art of Transition ${ }^{15}$ analiza la transición democrática chilena y argentina desde las categorías del género y la sexualidad, ya que permiten ver en transversal las políticas culturales que organizan la historia de las Américas. Para Masiello, la tensión entre lo exótico y lo legible, entre lo homogéneo y una heterogeneidad irreducible, entre la innovación y la "ausencia de pensamiento abstracto", son los estereotipos que definen la percepción global de los procesos culturales en América Latina, y refuerzan el imaginario de su «inferioridad» $\mathrm{y}$ "denigran sus impulsos hacia una conceptualización teórica independiente ${ }^{16}$. En su análisis, la entrada de los movimientos populares en la imaginación crítica a partir de los 1970 confluyó en un proyecto de Estado que le permitió, al mismo tiempo, hacerse de un proyecto en relación a sus sujetos marginales y construir un signo de resistencia a los centros metropolitanos. Para Masiello tanto el movimiento de mujeres como el de minorías sexuales del presente, están firmemente construidos en su voluntad de margen, periferia, minoría y subalternidad contestatarios al Estado y los poderes, y a través de este carácter opositor evalúa históricamente la incapacidad de las elites de articular la modernización como proyecto de justicia y distribución social. Por eso, la identificación con lo que Masiello llama los fuera de la ley (los malandras brasileños, los rotos chilenos, los villeros argentinos) consiste en que proveen a los intelectuales con modelos alternativos y resistentes de subalternidad respecto de la homogeneización mercantil del Estado neoliberal.

14. Al respecto, para una síntesis de posiciones al respecto cfr. GUZZETTI, Lorena y FRASCHINI, Mariano: "El movimiento feminista ante las políticas neoliberales en los noventa», en http://agendadelasmujeres.com.ar/index2.php?id=3\&nota=1804. Accedido el 18 de septiembre de 2006.

15. MASIELLO, Francine: The Art of Transition, Durham, Duke University Press, 2001.

16. Ibíd., pp. 25-26. 
La noción de fuera de ley del neoliberalismo ha creado, al igual que para Rodríguez, categorías criminales que sirven tanto para autorizar la naturaleza apocalíptica de la historia latinoamericana, y así generar consenso con políticas sociales y económicas que pueden llegar al genocidio, como para la más puntual función de producir una tensión irreconciliable entre las clases medias y las marginales ${ }^{17}$. Esto es metáfora de que la función redistributiva del Estado ya no es posible: el proyecto de la nación moderna ha fracasado, y los márgenes (mujeres, pobres, trabajadores, minorías sexuales y étnicas) parecen tener que conformarse con coincidir con alguna de las identidades que el mercado y los medios construyen para ellos. Aquí es donde se localiza una nueva entrada a las políticas culturales: una lectura desde los géneros sexuales y las sexualidades abre el espacio de nuevas prácticas democráticas que tienen lugar en lo menor. Así, la articulación entre el foco en las mujeres y las minorías sexuales no indica una alianza, sino que propone una lectura en correlato de los movimientos sociales en lo popular, que "desestabiliza» modelos de alteridad, mientras es muestra de la "ansiedad de los intelectuales respecto a su representación ${ }^{18}$. Las diferencias de géneros y sexualidades son uno de los espacios privilegiados para pensar las desigualdades sociales concretas como crítica del modelo de diversidad democrático neoliberal. De hecho, esto supone reconocer que las relaciones de violencia estructural son prioritarias para comprender el fenómeno de la violencia como aparato imperialista. Pero también, implica que esa violencia estructural sólo se percibe en las prácticas sociales concretas que involucran un análisis de los modos personales e históricos de violencia.

\section{LA HERENCIA POLÍTICA Y LA CRÍTICA AL MODELO DE LAS ONGS}

El desarrollo de los movimientos de mujeres y minorías sexuales en América Latina ha estado crecientemente articulado por la transformación del Estado, y por los programas de ajuste económico y social, a partir de comienzos de los 1980. La organización de esos movimientos tiene una larga trayectoria que comparte, sobre todo a nivel teórico, las tendencias y transformaciones del feminismo global (primera ola, segunda ola, feminismo de la diferencia, etc.). Pero la retirada del Estado y el empobrecimiento social ha supuesto tanto una intensificación como una diversificación de los objetivos de la lucha antidiscriminatoria. Debemos recordar aquí que, durante la segunda mitad del siglo $\mathrm{XX}$, las sociedades latinoamericanas atravesaron unos procesos de inestabilidad política, social y económica que supusieron, salvo casos aislados, una intensificación de la violencia estructural y graves crímenes contra los derechos humanos: dictaduras militares, guerras civiles, formación de guerrillas y cuerpos para-policiales, políticas de exterminio y persecución ideológica y étnica. En este contexto, el retorno a la democracia se realizó a través de una articulación del discurso de los derechos humanos y la memoria que se convirtió en el

17. Ibíd., p. 30

18. Ibíd., p. 41. 
horizonte privilegiado de la unificación y pacificación social. Pero esa unificación se produjo asimismo en un contexto de creciente fragmentación social y emergencia de agencias sociales que no sólo tenían reclamos específicos a los gobiernos, sino que además aspiraban a cambiar la noción misma de política. De allí la situación incómoda en que quedaron los colectivos de mujeres y minorías sexuales, que vieron incluidas crecientemente sus demandas en las legislaciones sin que, sin embargo, su experiencia de vida cotidiana parezca haberse transformado.

La articulación entre violencia y derechos humanos tiene ahora su foco en el desarrollo de la desigualdad bajo la democracia. De hecho, la transición a la democracia política no se tradujo en un cambio en las formaciones culturales de la opresión, que por cierto pocos esperaban. Esos procesos se realizaron en condiciones de expansión y consolidación del capitalismo global tecno-financiero, e incluyeron una creciente participación del tercer sector o postmodernización del sector de la industria de los servicios. Es imposible dar cuenta del estado actual de los movimientos de mujeres y minorías sexuales sin entender el impacto que han tenido el abandono del Estado de amplias zonas de los servicios sociales, el desmantelamiento de los ya precarios sistemas del Estado benefactor, y la pauperización y exclusión social de amplios sectores de la población.

La tercerización de las lógicas de la igualdad debe entenderse como un modo de articulación entre las políticas democráticas de la sociedad civil y la pobreza y marginación. Este vínculo es explorado históricamente por los colectivos de mujeres y minorías sexuales cuando se plantean su integración discriminatoria en los horizontes nacionales, particularmente a los partidos políticos, pero también a movimientos de resistencia armada o pacífica como el movimiento Zapatista. La tercerización de los movimientos de mujeres dependió de un uso político de la diferencia y diversidad social frente a la percepción de que el Estado en América Latina no podía hacer frente a la explosión de demandas particularistas, en muchos casos antagónicas. La aparición de ONGs constituye así un elemento central pero conflictivo en la producción de acciones para el cambio pacífico, ya que "terceriza» los reclamos (haciéndolas objeto de una profesionalización, jerarquización y clientelización) al precio de aislarlos del contexto de las demandas populares más amplias. De allí que la concepción de transformación de conflictos depende en gran medida de establecer una conexión entre justicia social y asistencia básica ${ }^{19}$. La transformación histórica de este vínculo entre justicia social y demandas básicas diferenciadas se complica ampliamente a medida que se produce la institucionalización del tercer sector, por varios motivos. Uno es la preocupación que produce el desplazamiento de las organizaciones de mujeres de la calle y la oposición a las instituciones políticas, esto es su función como estabilizadora del conjunto. Otro es el rechazo generalizado a la idea de que los reclamos se organizan en relación a un terreno

19. MARKowitz, Lisa y TICE, Karen: «Paradoxes of Professionalization. Parallel Dilemmas in Women's Organizations in the Americas», Gender \& Society, 16:6 (December 2002), p. 947. 
cultural homogéneo, aunque diversificado, que dependería del libre mercado. ${ }^{20}$ Lo que esta articulación requiere es, por el contrario, una definición del terreno social como constitutivamente desnivelado, es decir, donde la identidad de los agentes sociales no es previa a la experiencia que la define, ni guarda el mismo peso respecto del poder y las estructuras de desigualdad.

Markowitz y Tice se realizan entonces una pregunta para comprender este carácter desnivelado de las relaciones sociales, desnivel que ha tenido repercusiones en las iniciativas del sector de servicios: ¿qué sucede cuando las ONG apoyan el entrenamiento de pequeños emprendedores más que las protestas antiglobalización, aunque éstas últimas puedan tener más éxito y contribuir a la reducción de la desigualdad económica y doméstica? En efecto, varios problemas aparecen en esta pregunta. Markowitz y Tice hacen particular énfasis en el cambio de políticas globales de las ONG, en las que los donantes globales han tendido a privilegiar la transparencia institucional y la promoción al desarrollo, mientras dejan los aspectos de ayuda básica a las organizaciones caritativas, principalmente confesionales. Esto es percibido por los grupos marginados como una falta de sensibilidad a sus reclamos y como una muestra de menosprecio. Al mismo tiempo, los movimientos de mujeres han estado en América Latina históricamente articulados por el reconocimiento de que la identidad de género se construye en la intersección de factores étnicos, de clase y regionales o nacionales, y se teme que el proceso de profesionalización reproduce la jerarquización que se combate.

Nelly Richard historiza este proceso en el Chile de la transición post 1990, al estudiar cómo la profesionalización y mercantilización de amplios sectores del feminismo chileno requirió su adaptación a las políticas conservadoras del gobierno. Las tareas del feminismo chileno durante la dictadura, según Richard, se instalaron en la oposición democrática, y consistieron en establecer un frente solidario con otras fuerzas de liberación social, a la vez que además permitieron «descentrar y complejizar la referencialidad al poder del Estado, cuya versión totalizante y centralizante orientaba el entendimiento de la política tradicional ${ }^{21}$. La descripción de Richard es un buen ejemplo de una modalidad bastante extendida en América Latina de sus transiciones políticas. En primer lugar, un número importante de feministas abandonaron los movimientos sociales para

20. Como indica Flavio Rapisardi, Milton Friedman en Capitalismo y Libertad sostiene que «el mercado constituye el mejor modo de regulación social y política, ya que es capaz, por su impersonalidad, de separar el campo de las opiniones y de las nociones de bien (sostenidas por identidades particulares), de las actividades económicas, lo que garantiza la igualdad de acceso y de oportunidades de todas las minorías». Por otro lado, los liberales comunitarios como Rawls mientras reconocen la validez de los reclamos particularistas basados en la diferencia siguen predicando que los mismos no son «relevantes» para la construcción del consenso básico para el espacio social. RAPISARDI, Flavio: «Regulaciones políticas: identidad, diferencia y desigualdad. Una crítica al debate contemporáneo», en http://noa-codigos.blogspot.com/2006/08/ regulaciones-politicas-identidad.html. Accedido el 10 de septiembre de 2006.

21. RCHARD, Nelly: "La problemática del feminismo en los años de la transición en Chile», en www.globalcult.org.ve/pub/Clacso2/richard.pdf, p. 229. 
insertarse en los mecanismos estatales y supra-estatales, donde veían mayor probabilidad de expandir la conciencia femenina, a la vez que se buscaba mayor representación para las mujeres en los aparatos políticos y culturales del Estado. En segundo lugar, la creación del Servicio Nacional de la Mujer (SERNAM) implicó que se abandonaran las agendas críticas, y éstas se reorientaran hacia la relación entre mujer y familia que definió la política de concertación de la Democracia Cristiana. Tercero, supuso la creciente desvalorización pública de las posiciones más críticas y radicales (aquellas basadas en temas como el divorcio o el aborto) para permitir situar la agenda femenina en el contexto del mencionado terreno centrista. Finalmente, se privilegió un modelo "tecnificado de pragmatismo y eficacia», que tendió a ubicar en los centros de estudios universitarios y en las $\mathrm{ONG}$ la legitimidad de la producción de conocimientos sobre la mujer, conocimientos que eran funcionales al Estado, y que eventualmente supuso que "lo profesional desplazara a lo militante, y que lo operativo adquiriera mayor urgencia que lo discursivo» ${ }^{22}$. En otras palabras, Richard sugiere que la profesionalización sirvió para normalizar para abajo las demandas de los movimientos de mujeres, produciendo un discurso aceptable al programa de géneros del Estado, y una privatización de los espacios de debate e intervención sobre criterios técnico-racionales cuya consecuencia más relevante fue retirar al movimiento de mujeres del espacio público. Es cierto que las ONG permitieron, a partir de generar una estructura de relaciones plurales entre sociedad civil y organizaciones no estatales, una serie de acciones que descentralizaron al Estado como institución única en la toma de decisiones a la vez que abrieron el debate de las fronteras nacionales. Pero aún así su crítica es que, en última instancia, la tercerización del movimiento de mujeres lo puso en una relación de subordinación con el Estado que siguió una clara dirección conservadora, burocrática y técnica.

Ahora bien ¿cuál es la consecuencia de privilegiar la justicia social frente a los programas de ayuda y asistencia básica? El primer elemento a considerar es que la proposición «justicia social» es la enunciación de un problema. Es lo que se podría llamar un significante vacío, en el sentido de que su contenido (lo que designa la justicia social) va a depender de su articulación en un contexto hegemónico. En el caso chileno, pero como indiqué extensible a buena parte de las sociedades en procesos de democratización, justicia social supuso un reconocimiento formal de las reclamos que pasaron a satisfacerse individualmente y no como parte de una cadena de demandas sociales que en verdad era mucho más extensa y tenía su foco en la pobreza y la represión. De hecho las limitó sustancialmente. Así la noción de justicia social sancionó la exclusión social, e incorporó las gramáticas de géneros sexuales conservadoras a partir de fortalecer roles alrededor del hogar (madre y esposa) como necesarios para la «estabilidad democrática». En realidad, sabemos que este es un reclamo general de las feministas en situaciones de post-conflicto: no sólo su limitada participación y

22. Ibíd., p. 230. 
consulta en los programas de reconciliación y pacificación, sino además que sus intereses son rápidamente sacrificados al restablecimiento del statu quo.

De allí que algo que caracterizó las transiciones democráticas de México a Argentina fue la ampliación legislativa (leyes de divorcio, de patria potestad compartida, de reproducción y planificación familiar aunque muy restringidas, contra el acoso sexual, de igualdad de derechos laborales, pensiones), pero también que éstas se produjeron en la mayoría de los casos en contextos que mostraron las dificultades para cambiar tendencias culturales. La paradoja que trajo la última ola democratizadora fue un Estado con derechos políticos, incluido el de la diversidad cultural, pero sin derechos sociales, económicos y culturales que continuaron definidos por regulaciones culturales. Los ejemplos son desalentadores. Las feministas mexicanas se quejan de que la legislación estatal contra la violencia de género existe, pero las regulaciones culturales patriarcales dificultan su aplicación, y la tratan como casos de violencia doméstica o familiar ${ }^{23}$, en particular la violación, el asesinato y el aborto ${ }^{24}$. En el caso de las desalentadoras figuras sobre el acceso de mujeres y niños a los servicios sanitarios en Perú, incluidas las políticas eugenésicas como el Programa de Esterilización Quirúrgica Voluntaria que esterilizó aproximadamente 363.000 mujeres indígenas en los sectores más pobres y vulnerables ${ }^{25}$.

\section{LAS REGULACIONES CULTURALES DEL CONFLICTO}

Hemos visto que las feministas latinoamericanas han utilizado el cruce entre teorías de géneros y estudios culturales para cuestionar, por un lado, la tercerización de la solidaridad como reproductora de relaciones de clase y, por otro, para traer a la luz los límites de las teorías del conflicto que lo presuponen como un tipo de interacción a ser dirimida en el terreno neutral de la economía según el esquema demoliberal. Hemos visto también que ese terreno estaba limitado por las tensiones inherentes a un modelo que, mientras produce integración sobre un modelo trivial de diversidad cultural, en realidad restringe el acceso a través de crear las condiciones para una "política de la desesperación». En este contexto, se hace central pensar "el valor crítico de la diferencia» para analizar tanto las ideologías sociales autoritarias, como los modos de integración social en los debates sobre multiculturalismo democrático. Ese valor crítico de la diferencia se produjo como parte de una historización de las luchas sociales desde

23. AMNESTY INTERNATIONAL: "México. Briefing to the Committee on the Elimination of Discrimination against Women", 1 de junio del 2006, en www.amnesty.org/library/Index/ ENGAMR410312006?open\&of=ENG-373. Accedido el 18 de septiembre de 2006.

24. El caso del aborto merece una mención especial como caso de criminalización y discriminación por géneros sexuales. Está penalizado en toda América Latina, menos en Cuba. Es siempre ilegal, y simplemente se condona en casos especiales: cuando la vida de la madre está en peligro, violación o discapacidad probada. De allí los virulentos debates que atraviesa América Latina, al menos desde la Conferencia de Beijing, sobre derechos reproductivos.

25. AMNESTY INTERNATIONAL: «Perú: Poor and Excluded Women Denied of Maternal and Infant Health. Facts and Figures», 11 de julio de 2006, en www.amnesty.org/library/Index/ ENGMAR460182006?open\&of=ENG-373. Accedido el 18 de septiembre de 2006. 
los procesos mismos de discriminación y opresión, como mostró muy bien el debate alrededor del testimonio como espacio en el que los sujetos piensan sus propias condiciones de existencia y solidaridad. Se privilegió principalmente la crítica a la concepción de identidades del multiculturalismo al estilo anglosajón, ya que se consideraban al menos dos aspectos problemáticos. Por un lado, se reformuló, a través de la noción de antagonismo, la concepción de las identidades como "reclamos de autenticidad» que requiere la idea de que las identidades son previas al conflicto, ya que se los identificó con mecanismos triviales de diversidad cultural producidos por la industria cultural global. Frente este modelo de la autenticidad, se propuso que las identidades se organizaban en antagonismos en lo que Silvia Delfino llama «experiencias materiales de la desigualdad $»^{26}$. Por otro lado, se reformuló el modelo de representación por cuotas, que suponía entender los conflictos como meras luchas por el acceso a los circuitos de distribución y consumo sin contenido de clase. En otras palabras, se estableció una mirada crítica hacia ciertos contenidos del liberalismo pero también del comunitarismo ${ }^{27}$.

Mabel Bellucci y Flavio Rapisardi ${ }^{28}$ entienden el sentido del «valor crítico de la diferencia" como reconocimiento de que las identidades de las mujeres y de las minorías sexuales aparecen en el horizonte de desigualdades de clase social, aunque admiten que las narraciones de clase han cambiado sustancialmente. ¿En qué consiste entonces el valor crítico de la diferencia? Se lo identifica con "la lucha política en tanto instancia articuladora de las demandas por la distribución de bienes materiales y la superación del irrespeto cultural». Su crítica a las identidades multiculturales se produjo alrededor de la pregunta ¿qué define una «identidad verdadera» en el contexto de la globalización neoliberal? Para ellos una identidad verdadera es aquella que no es una "simple fragmentación del mercado", "ni un simple modo de acceso a los circuitos de distribución y consumo", sino que debe encerrar una lucha contra las formas hegemónicas totalizadoras, en la que se aspira a la justicia social sin renunciar a las reivindicaciones particularistas.

El objetivo de esta distinción es ofrecer al Estado un espejo en el que éste se hace responsable por las operaciones de exclusión y marginación social que

26. DelFinO, Silvia: «Género y regulaciones culturales», en F. Forastelli y X. Triquell (comps.): Las marcas del género. Configuraciones de la diferencia en la cultura, Córdoba, Centro de Estudios Avanzados-The British Council, 1999, pp. 67-84. Al respecto Delfino dice: «se concibe al antagonismo como una materialidad que puede tener, en un momento histórico específico, el aspecto de una diferencia cultural, étnica, religiosa, genérica, generacional o de orientación sexual en tanto experiencia concreta de la desigualdad» (p. 69).

27. Así, Flavio Rapisardi observa que: «El liberalismo oblitera la diferencia y desdibuja la desigualdad en su afán de establecer un plano neutral de negociación; y el multiculturalismo comunitarista la considera como un tipo especial de «diferencia cultural» o, como ya dije, como mera "función» que imposibilita los distintos dispositivos de tolerancia al producir una radicalización de la diferencia cultural», RAPISARDI, Flavio: Regulaciones políticas..., op. cit.

28. BELLUCCI, Mabel y RAPISARDI, Flavio: «Alrededor de la identidad. Las luchas políticas del presente», Nueva sociedad, 162 (Julio-Agosto 1999), pp. 41-53. 
realiza mientras propone retóricas ciudadanas formales de igualdad e integración. Las identidades surgen en coyunturas históricas concretas, y desde allí su funcionamiento político tiene un carácter retroactivo: a través de las luchas involucradas en la constitución de la identidad podemos ver el proceso de su adjudicación a un lugar histórico y a un tipo de conflicto específico. De hecho, las feministas y activistas queer fortalecieron los procesos de identificación e igualación, y enfocaron en los modos en que los procesos del neoliberalismo estaban generando una red de integración que define a sus sujetos no por su mera exclusión de la estructura social, sino por precisamente por su función subalterna en ella. De allí la función cultural de la violencia de Estado según Silvia Delfino, que produce una serie de discursos sobre la inadaptación social para cubrir de algún modo aquellas áreas que no pueden ser integradas a la justicia social. Por eso algunas de las rearticulaciones de género más fascinantes se dieron en el contexto del debate sobre prostitución y travestismo, ya que supusieron que el debate sobre géneros sexuales se vinculara al de heteronormatividad. La activista travesti Lohana Berkins, por ejemplo en "Transgenericidad: la construcción/reconstrucción de nuestra identidad» dice:

«Elijo la palabra travesti porque es importante resignificar el término con el cual se refieren a nosotras... Tenemos diferencias físicas y culturales con las mujeres. Acepto que hemos sido criadas con toda una carga patriarcal... [pero] somos, como las mujeres, traidoras del patriarcado, y eso es algo que muchas tenemos que pagar con nuestras vidas. (...) El género que queremos construir no es el femenino, pero no podemos negar que algunas de las características que asumimos se encuentran en las mujeres. Pero aquí tenemos dos opciones: somos las mujeres que consume el sistema, lindas, dulces, etc., o nos identificamos con quienes luchan por el aborto, por la libre elección sexual y con las bolivianas que lucha por sus tierras (...) Es aquí donde nosotras somos lo que queremos ser en solidaridad contra un enemigo común... que se manifiesta en la opresión social -desprecio y falta de trabajo- y en la violencia institucional. Somos mujeres y somos un escándalo, esta es una respuesta a la condena. ${ }^{29}$

En este sentido, la percepción general fue que los movimientos de mujeres y de minorías sexuales se define desde su articulación en lo que se denominan las "contradicciones principales» de las sociedades dependientes, y su carácter sexual no es aleatorio sino constitutivo de esas contradicciones. El vocabulario de la crítica a la dominación sexista se renovó en un contexto donde se volvió equivalente a la crítica al racismo, la homofobia, el antisemitismo y el etnocentrismo, ya que los procesos de conflicto previos habían hecho evidente que los objetivos de la represión y persecución se recortaban contra ciertos grupos, pero también que los habían construido previamente. Así, para Rapisardi y Bellucci, la producción de estas equivalencias supone que no existe un modelo único de luchas contra la desigualdad, sino «una multiplicidad de luchas que pueden ser diferentes entre sí, como diferentes son las mujeres de acuerdo a su condición

29. Citada por RAPISARDI, Flavio: Regulaciones politicas..., op. cit. 
de clase, etárea, cultural, étnica, su nacionalidad y su opción sexual». Ahora bien, este reagregamiento de equivalencias preparó asimismo el terreno para la formación de alianzas, en las que las mujeres históricamente abren el terreno institucional y simbólico para otras organizaciones políticas y sociales. Por eso, para el activismo queer, el pasaje de los grupos de reflexión y pertenencia a la resistencia colectiva implicó desarrollar tanto las contradicciones presentes en el discurso liberal de la igualdad y la comunidad, como deconstruir en una dirección más plural un agente social en particular, «el solipsismo blanco de clase media». La pregunta pasa a ser: ¿la pluralización a la que fue sometida la noción de identidad, deconstruyendo las implicaciones excluyentes y opresivas de las identificaciones culturales de género, agota el potencial emancipatorio de los movimientos de mujeres y de las minorías sexuales?

Parte de la respuesta a este problema fue establecer un sujeto verdadero de la acción como hemos visto, ya que permitió contestar a un Estado vocinglero que produce un discurso universalista de integración, mientras realmente administra redes discriminatorias hacia mujeres, jóvenes, trabajadores o minorías sexuales y étnicas. Pero una parte importante, asimismo, resultó de privilegiar la idea de que el carácter crítico de las operaciones de identidad se produce hoy en un contexto con profundas desigualdades de clase, un aspecto sobre el que existen fuertes disensiones ya que parece reinscribir una forma de esencialismo. Por eso, las demandas de los colectivos de mujeres y minorías sexuales no tienen como objetivo conquistas culturales de acuerdo a su pertenencia a un segmento definido por el mercado impersonal de la economía, sino que implican un reordenamiento profundo y distribución justa y respetuosa de los bienes simbólicos y materiales. Sabemos que esto revierte en el panorama internacional de la Teoría Social en un debate sobre la determinación de clase frente a la heterogeneidad de reclamos popular-democráticos ${ }^{30}$, y esta es sin duda una de las grandes contribuciones de estos movimientos. Así, los activistas queer han recontextualizado la oposición entre democracia y lo popular siguiendo a Nancy Frazer, al indicar que el dilema entre redistribución y reconocimiento es falso, ya que las dimensiones culturales y materiales se entrecruzan. Así, el irrespeto cultural se traduce en una situación de desventaja en la redistribución de bienes económico-culturales mientras la desigualdad económica imposibilita la participación igualitaria en la construcción de la cultura.

El proceso de pasaje de las luchas por la representación se ha presentado cada vez más vinculado a las luchas antidiscriminatorias y anti-represivas. Para ello, se desarrolló y especificó, en el caso de Argentina, la noción de regulaciones culturales proveniente de los estudios culturales marxistas ingleses. Esta noción sirvió para dar cuenta de una tensión entre el marco normativo que mide la aplicación de la ley, y la existencia de un conjunto de actividades no criminales, pero penalizadas en muchos casos anticonstitucionalmente, por códigos locales de contravenciones (por ejemplo, la figura del merodeo o la oferta de sexo

30. Para una revisión de esta tensión, ver LACLAU, Ernesto: Populist Reason, Londres, Verso, 2005. 
en lugares públicos) que están en manos de la policía ${ }^{31}$. Ahora bien, en lugar de insertar este debate en la tensión clásica sobre América Latina alrededor el carácter formal de sus instituciones, que implica hacerle un juego a la noción neoconservadora de que la democracia es no sólo ineficiente sino además cara frente a la que hay que operar con un modelo administrativo, el desfase entre la normativa y su regulación cultural se construyó para entenderlo como un modo de discriminación en sí mismo. Silvia Delfino y Guadalupe Salomón ${ }^{32}$ han analizado recientemente esta relación entre norma y regulación como una configuración material compleja de la experiencia compartida de desigualdad que atraviesa el Estado, la sociedad civil y los medios masivos de comunicación. Por un lado, requiere una investigación sobre las ideologías sociales que permitieron, y permiten, la discriminación, persecución y el exterminio no sólo como un plan organizado desde los aparatos del Estado, sino desde los consensos sociales que los vuelven "inexorables». Por otro lado, hacen hincapié en «el tipo de políticas y procedimientos que regulan la vida pública y personal a partir de efectos discriminatorios en la constitución de las regulaciones legales y policiales». Su carácter discriminatorio radica en que dichas regulaciones recaen sobre mujeres pobres, trabajadores y trabajadoras sexuales, travestis, vendedores ambulantes o manifestantes anti-globalización. En efecto, la estrategia del Estado democrático en Argentina para controlar el conflicto se caracteriza por reprimir sujetos y grupos que primero son señalados como peligrosos, y luego son sancionados y criminalizados por el lugar que se les dio. Para Delfino y Salomón, esta represión se define por una articulación de formas de poder y autoridad que regulan la segmentación en el acceso al trabajo, la educación o los bienes simbólicos, mientras por otro lado, excluyen de la participación activa a gran parte de la población ${ }^{33}$. Se restringe la participación pública a la vez que las decisiones se llevan a cabo crecientemente por expertos de gestión y control organizacional. Pocos olvidan cuando el gobierno de la ciudad de Buenos Aires, ante la protesta masiva que se generó ante la crisis del 2001, invitó a Rodolfo

31. Hacia comienzos de la presente década, la municipalidad de Buenos Aires propone reemplazar el Código de Contravenciones vigente basado en Edictos Policiales (que otorgan a la policía capacidad de juez de primera instancia en una serie de contravenciones), por un Código de Convivencia Urbana. Esto despertó un debate áspero entre diversos sectores sociales.

32. DELFInO, Silvia y SALOMÓN, Guadalupe: «Regulaciones culturales y luchas políticas: el caso del Código Contravencional de la Ciudad de Buenos Aires", Revista Jurídica de la Universidad Interamericana de Puerto Rico, Facultad de Derecho, XXXVIII:1 (septiembre-diciembre 2003). Consultado en: noa-codigos.blogspot.com/2006_08_23_noa-codigos_archive.html - 618k. Accedido el 9 de septiembre de 2006.

33. Recordemos que, aunque con altibajos, los índices de pobreza oficial para el segundo semestre del 2004 del Instituto Nacional de Estadísticas y Censos (INDEC) indicaban que el 40,2 \% de la población urbana de Argentina era pobre, y la indigencia llegaba el $15 \%$. En su peor momento, para octubre del 2002, el mismo índice de hogares pobres era del $45,7 \%$ y el de personas un $57,5 \%$; la indigencia para ese periodo había trepado al 19,5\% y el 27,5\% respectivamente ( La pobreza argentina. La situación social», www.cambiocultural.com.ar/actualidad/pobreza.htm. Accedido el 9 de septiembre de 2005). 
Giuliani, el ex alcalde de Nueva York y famoso por su política de mano dura contra la criminalidad, para asesorar sobre temas de seguridad urbana.

Culturalmente, la crisis y la violencia son explotadas desde los medios masivos, a través de los formatos testimoniales y de noticias, que exhiben las diferencias de géneros, raza, nacionalidad o sexualidad en un mercado de la autenticidad, tanto para dirimir reclamos como para construir perfiles de grupos problemáticos sin una reflexión sobre las condiciones de marginalidad, pobreza y exclusión. Estos perfiles son utilizados como vimos para confirmar la peligrosidad atribuida al grupo, pero también para fortalecer la presencia policial en áreas que deberían ser de desarrollo social (como en el caso de los chicos de la calle, la prostitución o el trabajo en negro) o judiciales (como la violencia doméstica o contra las prostitutas).

Silvia Delfino ${ }^{34}$ ha vinculado este modo de conflicto y resistencia en la idea de que el Estado funciona en la Argentina como un complot a la vista cuya trama es el secreto. Habíamos indicado ya que los estudios de la paz estudian la relación entre violencia personal (visible) y violencia estructural (invisible); y también que Confortini critica que esta distinción utiliza una versión deficitaria de poder. ¿En qué consiste esta relación para los activistas queer? Para Delfino, el secreto se institucionaliza como un modo de violencia ya que, en vez de ser una prerrogativa de los sujetos (privacidad), se construye como un modo de aislamiento y de control social. Esto se debe a que el Estado atribuye ese secreto a ciertos tipos de perfil social como desestabilizadores, mientras actúa distanciándose de los efectos que sus políticas producen ya que se reafirma en su rol de mero administrador. Por eso, las diferencias de géneros, orientación sexual, étnicas o de edad son un efecto de la distribución económica pero también de autoridad y, aunque no pueden subsumirse en la categoría clásica de clase social, la requieren. El problema, sobre el que Delfino vuelve en diversas intervenciones, es que la relación entre peligrosidad y violencia es reversible y por lo tanto las hipótesis de conflicto no alcanzan a explicar las interacciones sociales, sino que simplemente las localizan. Lo que define la regulación cultural de la violencia es una injuria material, que Delfino trabaja como un tipo de relación reversible entre la burla y el insulto, y es característica del menosprecio y la derogación de los derechos de quienes han sido previamente marginados. La privación de derechos y el menosprecio, por lo tanto, sólo sancionan retrospectivamente esa situación de marginación económica. Por eso, la violencia no es resultado de una situación de ambigüedad o ambivalencia de valores o pobreza económica, sino una operación de articulación hegemónica que es preciso desarmar.

Concluyendo, ¿en qué podemos ver el contacto entre la propuesta de la comunicación para la Paz y la transformación pacífica de conflictos de Martínez Guzmán y las propuestas antidiscriminatorias de las feministas y activistas

34. Por ejemplo, ver Delfino, Silvia: "Cómo se cuenta la historia oficial?», Documentos de Trabajo del Instituto Rojas, Universidad de Buenos Aires, 2004, mimeo. 
queer? En la necesidad de mantener abierta la noción de conflicto para su transformación pacífica. En vez de negar el carácter inconmensurable entre conflicto y pacificación, Martínez Guzmán ha observado inspirado en Honneth, que el reconocimiento como condición para la transformación pacífica de conflictos depende de vincularlo con formas del menosprecio: falta de respecto contra la integridad física, como desposesión de derechos y exclusión de la comunidad jurídica y como «menosprecio cuando una determinada forma de vida se considera indigna y se 'hieren' los sentimientos de formas de vida diferentes $»^{35}$. El rechazo al fundacionalismo y la búsqueda de narraciones plurales es un terreno ético y político de reconstrucción social de competencias para la Paz. Requiere también que, mientras consideremos al conflicto como constitutivo de las relaciones humanas, exploremos lógicas sociales que permitan pensar otros modos de dar cuenta de las diferencias sociales y la diversidad cultural. El énfasis que le da al desarrollo de una "gramática de los sentimientos» creo que es compatible con la noción de "experiencia de la desigualdad", ya que en ambos casos se trata de traer a la luz algo que ha sido obliterado. Nos plantean terrenos de exploración para la Paz y el conflicto en los que la experiencia nos dice que ninguna opción está clausurada. 